\title{
commentary Explanatory paradigms for professional boundary violations
}

\author{
Gwen Adshead \\ Commentary on... boundary violations in therapy and sexual \\ boundary violations ${ }^{\dagger}$
}

Gwen Adhsead MBBS, MRCPsych, MA, MSt is a forensic psychiatrist and psychotherapist. She has a longstanding interest in professional ethics and the reasons that professionals breach rules and guidelines in their behaviour with patients. She was Chair of the Royal College of Psychiatrists' Ethics Committee between 2001 and 2005, and she has served on the College's Professional Practice and Ethics Committee since 2010 as a co-opted member. She gave evidence to the Kerr/Haslam Inquiry into sexual boundary violations by psychiatrists, and was a

founder member of a voluntary group (which later became the charity

Witness) that supported survivors of sexual abuse by professionals. She has worked for the Clinic for Boundaries Studies with Jonathan Coe and was awarded a Winston Churchill Travelling Fellowship to study interventions for doctors who show disruptive behaviour at work. In 2013 she was awarded the Royal

College of Psychiatrists' President's Medal for her work in mental health ethics.

Correspondence Dr Gwen Adshead, Ravenswood house, Mayles Lane, Hampshire, P017 5NA, UK.

Email: g.adshead@nhs.net

\section{Copyright and usage}

(C) The Royal College of Psychiatrists 2018

${ }^{\dagger}$ See pp. 366-373 and 374-383, this issue.

\section{SUMMARY}

In this commentary, I draw on Hook \& Devereux to explore the role of insecure attachment in boundary-violating doctors. I also explore the potential contribution of personality dysfunction in that small proportion of doctors who breach professional boundaries.

\section{DECLARATION OF INTEREST}

G. A. worked with Dr Hook at St George's Hospital, London, and has also worked at the Clinic for Boundaries Studies, where he has worked.

\section{KEYWORDS}

Ethics; psychosocial interventions; personality disorders.

I am grateful to both the Editor of BJPsych Advances and to the authors of these two stimulating articles (Hook 2018a,b) for an opportunity to reflect on this most important of topics. Reading these articles reminded me of a conversation about sexual boundary violations by therapists that I had in 1990 with a senior and highly respected professor of psychiatry who was a leader in mental health ethics. I suggested that sexual boundary violations by psychiatrists and psychotherapists were a real problem that needed to be discussed by the Royal College of Psychiatrists; he demurred and dismissed my concern, saying 'All patients fall in love with their therapists'. It is fair to say that we have come a long way since then; this journal itself published a useful review article by Sarkar (2004) and the College has published two editions of advice about boundaries in psychiatric practice entitled Vulnerable Patients, Vulnerable Doctors (Royal College of Psychiatrist 2013, 2017). However, given that psychiatrists are still over-represented among doctors in the UK referred to the General Medical Council (GMC) for misconduct, especially sexual boundary violations, these articles are timely and valuable for seniors and trainees alike.

\section{Why does it happen?}

The intriguing question to me as both a doctor and a therapist is why this type of misconduct persists. Although teaching and training in medical ethics have greatly improved over the past 30 years, I do not think it is unfair to say that, for many young doctors, the most memorable ethical principle that they can articulate on graduation is 'Do not have sexual relationships with patients'. Yet a significant minority of intelligent thoughtful doctors distort their cognitions, and blind themselves to facts and consequences, in pursuit of a relationship that they must know at some level is essentially wrong and abusive and therefore likely to fail. I find it bitterly poignant to read the accounts of sexual boundary violations by doctors that are initially couched as 'successful relationships', only to end up with the referral to the GMC when either party walks away. The GMC rightly takes the view that these relationships must be assumed to be exploitative of the patient's vulnerability at some level; and that the physician is responsible for ensuring that the professional dialogue and interaction stays focused on the patient and their needs. The domain of healthcare cannot simultaneously be the domain of seeking a mate.

\section{Dysfunctional attachment styles}

So why do doctors do this? There are a number of typologies of 'offender' and potential theories to explain why men and women who are otherwise prosocial rule keepers allow themselves to break this most ancient of rules. One potential line of study may be to use an explanatory paradigm based on attachment theory. The attachment system in mammals is activated in caregiving and careeliciting situations; but insecure attachment style may lead to aberrant caring behaviours and responses to dependence in others. Studies of insecure attachment in parents have found that insecurity of attachment can be associated with profound failures of care to the vulnerable, including insensitive, hostile and abusive behaviours (Reder 2001). 
In relation to doctors as carers, Vaillant et al (1972) were possibly the first to suggest that behavioural problems in doctors might be related to their relationships with their fathers. In their second article Hook \& Devereux (2018b) cite the study by MacDonald et al (2015) which found high levels of insecurity of attachment in doctors referred to a therapy programme for professional boundary violations. Insecure attachment might explain the adverse idealising transference described by Hook $\mathcal{E}$ Devereux (2018a), because idealisation is a key aspect of dismissing/avoidant attachment strategies. The dismissing stance deactivates distressing emotions and keeps them out of consciousness, and this results in both conscious dismissal of need ('I'm fine, I don't need help') and unconscious idealisation processes which keep painful or disturbing affects and thoughts out of consciousness. The dismissing attachment strategy is found in about $20 \%$ of ordinary community populations, but in about $60 \%$ of people who break social rules (Levinson 2004).

\section{Personality dysfunction}

Another related possibility is to consider the role of personality dysfunction in doctors who breach professional boundaries. Using traditional classificatory methods, one would not expect to find high levels of personality disorder in doctors; trainees are selected for personality strength and resilience, and behaviourally they rarely struggle with social rules across their lifespan. However, a dimensional approach to personality difficulty and disorder offers an alternative view that is both more sophisticated and clinically useful. Both DSM-5 and the draft ICD-11 invite clinicians to think about personality dysfunction in terms of degrees of severity (Crawford 2011; Hopwood 2011; Tyrer 2018); this echoes studies by occupational psychologists which suggest that personality strengths may become weaknesses under environmental stress (Kaiser 2011).

One possible framework for understanding how otherwise prosocial doctors come to let themselves do antisocial things is in terms of an exacerbation of mild personality dysfunction by stress. In relation to doctors and therapists, the kinds of stressor that might make personality difficulty or dysfunction worse are attachment-specific stressors: changes in caregiving role at work or at home. Changes in caregiving role at home can include the birth of a new child, the departure of an older child, the death of an elderly parent and, of course, marital breakdown. Stressful changes in caregiving role at work are especially problematic for doctors who currently work in the National Health Service (NHS), as they experience a doubling of their workloads but a loss of professional autonomy and the withdrawal of professional infrastructures that make the work possible.

\section{Rehabilitation and prevention}

I want to conclude with some comment about the provision of therapy for doctors and therapists who breach sexual boundary violations. The most violent and disordered of sexual offenders are automatically offered interventions while in prison as part of their rehabilitation, but no such programme is routinely offered to doctors who breach professional boundaries, except to some extent by the Clinic for Boundaries Studies. It is time that such a programme was offered free of charge to doctors after any finding of unfitness to practise by the Medical Practitioners Tribunal Service (MPTS), perhaps in cooperation with services such as the NHS Practitioner Health Programme in London. Such a programme could also be offered when there are early concerns about unboundaried behaviour, to prevent a fall down the 'slippery slope'. Enlightened self-interest would suggest that it is in everyone's interest to help these colleagues and learn more about how they came to offend.

\section{References}

Crawford MJ, Koldobsky N, Mulder R, et al (2011) Classifying personality disorder according to severity. Journal of Personality Disorders, 25: 321-30. Hook J, Devereux D (2018a) Boundary violations in therapy: the patient's experience of harm. BJPsych Advances, 24: 366-373.

Hook J, Devereux D (2018) Sexual boundary violations: Victims, perpetrators, and risk reduction. BJPsych Advances, 24: 374-383.

Hopwood CJ, Malone JC, Ansell EB, et al (2011) Personality assessment in DSM-5: empirical support for rating severity, style, and traits. Journal of Personality Disorders, 25: 305-20.

Kaiser RB, Hogan J (2011) Personality, leader behavior, and overdoing it. Consulting Psychology Journal: Practice and Research, 63: 219-42.

Levinson A, Fonagy P (2004) Offending and attachment: the relationship between interpersonal awareness and offending in a prison population with psychiatric disorder. Canadian Journal of Psychoanalysis, 12: 225-51.

MacDonald K, Sciolla AF, Folsom D, et al (2015) Individual risk factors for physician boundary violations: the role of attachment style, childhood trauma and maladaptive beliefs. General Hospital Psychiatry, 37: 489-96.

Reder P, Duncan S (2001) Abusive relationships, care and control conflicts and insecure attachments. Child Abuse Review, 10: 411-27.

Royal College of Psychiatrists (2013) Vulnerable Patients, Safe Doctors: Good Practice in Our Clinical Relationships (2nd edn) (College Report CR180). Royal College of Psychiatrists.

Royal College of Psychiatrists (2017) Sexual boundaries in clinical relationships (College Report CR205). Royal College of Psychiatrists.

Sarkar SP (2004) Boundary violation and sexual exploitation in psychiatry and psychotherapy: a review. Advances in Psychiatric Treatment, 10: 312-20.

Tyrer P, Mulder R (2018) Dissecting the elements of borderline personality disorder. Personality and Mental Health, 12: 91-2.

Vaillant GE, Sobowale NC, McArthur C (1972) Some psychologic vulnerabilities of physicians. New England Journal of Medicine, 287: 372-5. 